\title{
High-resolution models of subduction zones: Implications for mineral dehydration reactions and the transport of water into the deep mantle
}

\author{
Peter E. van Keken and Boris Kiefer \\ Department of Geological Sciences, 425 E University, 2534 CC Little Building, University of Michigan, Ann Arbor, \\ Michigan 48109-1063,USA. (keken@umich.edu; bkiefer@umich.edu)
}

\section{Simon M. Peacock \\ Department of Geological Sciences, Box 871404, Arizona State University, Tempe, Arizona 85287-1404, USA. (simon.peacock@asu.edu)}

[1] Arc volcanism is intimately linked to mineral dehydration reactions in the subducting oceanic mantle, crust, and sediments. The location of slab dehydration reactions depends strongly on the temperature and pressure conditions at the top of the subducting plate and hence on the detailed thermal structure of subduction zones. A particularly important physical property of subduction zone thermal models is the viscosity of the mantle wedge. The introduction of an olivine rheology, with appropriate stress and temperature dependence, focuses flow into the tip of the mantle wedge. This leads to a temperature increase of a few hundred degrees in the wedge and the top of the slab as compared to the isoviscous case. Sensitivity tests show that this conclusion is robust under a variety of subduction zone parameters. The new high-resolution finite element models are used to reevaluate the thermal structure of the Honshu and Cascadia subduction zones using the more realistic olivine rheology. For Honshu, the model predicts slabmantle interface temperatures of $\sim 800^{\circ} \mathrm{C}$ beneath the volcanic front. Deeper parts of the subducting oceanic crust and upper mantle remain relative cool (e.g., the subducted Moho beneath the volcanic front is $\sim 400^{\circ} \mathrm{C}$ ) because of the rapid subduction of old Pacific lithosphere. High interface temperatures are consistent with $\mathrm{Th}$ and Be data, indicating sediment melting, whereas cooler crustal temperatures are consistent with boron evidence, indicating lower temperature dehydration. The strong temperature gradient at the top of the subducting plate may thus reconcile conflicting estimates of slab temperature in subduction zones that are characterized by rapid subduction of mature oceanic lithosphere. Low temperatures persist to great depth in the shallow upper mantle of the subducting plate, which allows for water transport in the form of hydrous minerals to the deep mantle. The thermal structure of the Cascadia subduction zone is markedly different because of the age of the incoming lithosphere and low subduction speed. In this case, shallow dehydration and melting of the subducting crust and lithosphere is predicted.

Components: 9085 words, 13 figures.

Index Terms: 1010 Geochemistry: Chemical evolution; 8120 Tectonophysics: Dynamics of lithosphere and mantlegeneral; 8125 Tectonophysics: Evolution of the Earth; 3902 Mineral Physics: Creep and deformation.

Keywords: Petrology; Dynamical modeling; Honshu; Cascadia; Nonlinear rheology.

Received 15 October 2001; Revised 2 July 2002; Accepted 18 July 2002; Published 22 October 2002.

van Keken, P. E., B. Kiefer, and S. M. Peacock, High-resolution models of subduction zones: Implications for mineral dehydration reactions and the transport of water into the deep mantle, Geochem. Geophys. Geosyst., 3(10), 1056, doi:10.1029/ 2001GC000256, 2002. 


\section{Introduction}

[2] The dynamics of subduction zones form the key to a better understanding of earthquakes, volcanism, plate tectonics and the thermal and chemical evolution of the Earth. Of particular interest is the thermal structure, which dominates the buoyancy and rheology that govern the largescale dynamics of the mantle wedge and subducting plate. In addition, detailed knowledge of the temperature distribution is essential to understand the conditions for the generation of arc volcanism. Complementary approaches help to constrain the thermal structure of convergent margins. For example, the chemistry of arc magmas and the records of metamorphic events help constrain pressure-temperature-time paths. Seismically observed velocities, anisotropy and attenuation are linked to temperature and flow conditions in the slab and mantle wedge. Computational models based on conservation principles allow to predict the temperature distribution under given assumptions about subduction geometry and physical conditions.

[3] A creative interplay between the various approaches is needed since the uncertainties in determining the detailed thermal structure remain large. For example, there is conflicting evidence from the geochemistry of arc lavas regarding the temperature distribution in the subducting slab at depth. On the one hand, studies of high-pressure metamorphic rocks indicate that boron depletion is largely complete by amphibolite facies conditions $\sim 700^{\circ} \mathrm{C}$ which suggests that the relatively high B contents and high $\mathrm{B} / \mathrm{Be}$ ratios observed in arc basalts are related to low temperature, subsolidus dehydration reactions in the subducted oceanic crust [Bebout et al., 1993; Leeman, 1996]. On the other hand, Johnson and Plank [1999] have argued for relatively high slab temperatures based on $\mathrm{Be}$ and Th systematics, which suggest sediment melting. Their recent dehydration and melting experiments on pelagic sediments indicate that slab surface temperatures should exceed $\sim 775-800^{\circ} \mathrm{C}$ at $\sim 2-3 \mathrm{GPa}$. As a consequence, it is difficult to reconcile the interpretation of $\mathrm{Th}$ and $\mathrm{Be}$ data with that of B data if the release of these elements originates at the same depth in the subducting slab.
[4] Potentially even larger differences exist in the predictions from forward model calculations. Aside from the intrinsic differences in modeling approaches [e.g., Toksöz et al., 1971; Peacock, 1992; Kincaid and Sacks, 1997; Peacock and Wang, 1999; Peacock, 2002], fundamental input parameters to the models remain uncertain. These include the role of shear heating along the seismogenic zone and the description of the corner flow in the mantle wedge, which is governed by the geometry and rheology of the mantle wedge and overriding plate [Peacock, 1996].

[5] The purpose of this paper is twofold. First, we investigate the sensitivity of the thermal structure at the Honshu subduction zone to the assumed mantle wedge rheology by comparing constant viscosity results with those obtained with a stressand temperature-dependent olivine creep law. Second, we focus on the differences in the thermal structure of the Honshu (fast subduction of old lithosphere) and Cascadia (slow subduction of young lithosphere) subduction zones to address the potential for water transport into the deep mantle by hydrous minerals.

\section{Modeling Approach}

[6] The modeling of the thermal structure of subduction zones follows a standard approach in which a kinematically prescribed slab drives a dynamic cornerflow in the wedge under the stationary overriding plate (Figure 1). Although this model is partly kinematic, it incorporates the dominant flow processes in subduction zones and has been used extensively in studies of the slab/wedge thermal structure [e.g., Peacock, 1990; Davies and Stevenson, 1992; Furukawa, 1993; Peacock and Wang, 1999]. To date, most studies have used an isoviscous flow model in the wedge which allows for description of the induced flow through an analytical cornerflow solution [Batchelor, 1967] or efficient numerical evaluation.

[7] Accurate modeling of the mantle wedge is subject to considerable uncertainty. Some of the uncertainties include: (1) The depth at which the subducting slab and overriding plate become fully coupled. Commonly the downdip limit of the 


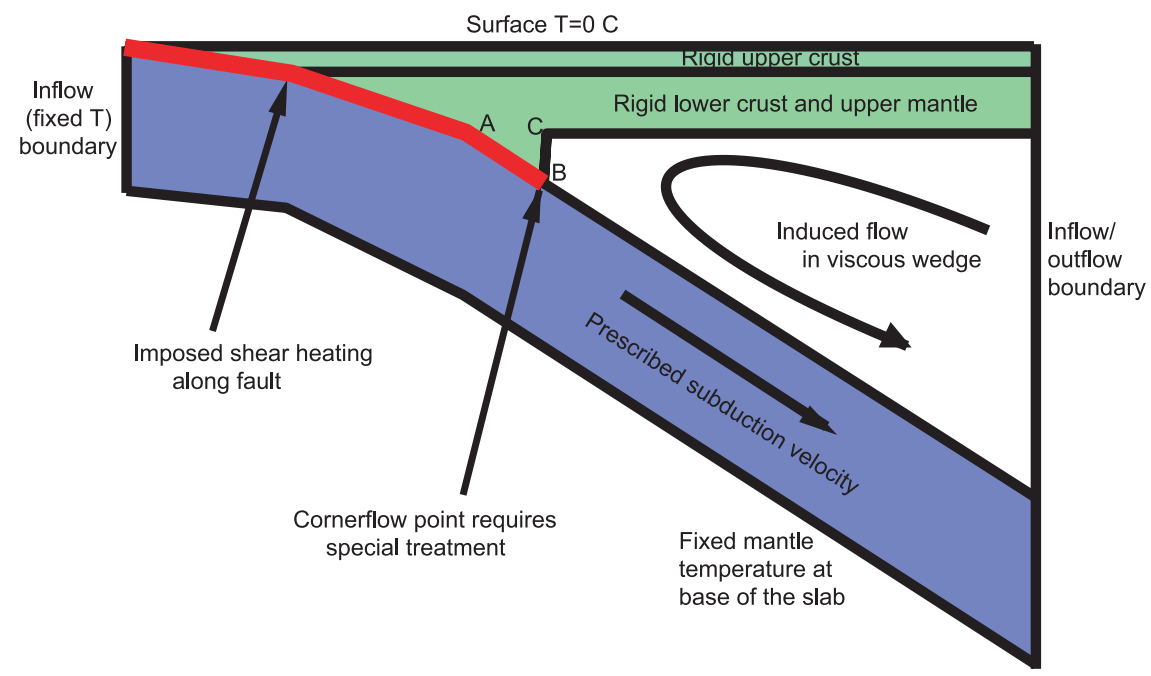

Figure 1. Cartoon of the geometry of the 2D subduction model. The slab is kinematically prescribed with constant speed that is parallel to the surface of the slab. Shear heating is imposed along the plate interface from the surface to point B. The subducting slab induces flow in the mantle wedge under the rigid overriding plate.

seismogenic zone [Tichelaar and Ruff, 1993] is used for the wedge tip, but there is considerable uncertainty in both the downdip limit and the location of the forearc Moho. (2) The geometry and physics of the wedge tip, which is likely cooled by the subducting plate [Kincaid and Sacks, 1997] and potentially hydrated [Peacock, 1993]. (3) The mathematical singularity that is caused by the discontinuous transition from the decoupled interface from the trench to wedge tip and the coupled interface along the base of the wedge. (4) The rheology of the wedge flow is most likely very variable due to strong variations with stress, temperature, and degree of hydration [Karato, 2002]. If the viscosity is sufficiently low, buoyancy driven convection may become important.

[8] In this paper we focus in particular on the role of temperature- and stress-dependent rheology of the mantle wedge and its influence on the temperature distribution in the subducting crust and mantle. We will first reevaluate the thermal structure of the Honshu subduction zone using a model that is similar to the one presented by Peacock and Wang [1999]. We shall refer to this paper as PW99 in the remainder of this paper.

[9] In following PW99 we assume a sharp transition between the motion along the fault and the viscous deformation below the corner point. On the one hand, this is a convenient assumption since it imposes a rheological description on a region of which the deformational characteristics are not well known. On the other hand, this introduces a mathematical difficulty, since the sharp transition causes a stress singularity in the description of boundary conditions for viscous flow in the wedge. There is an analytical and well-behaved solution that exists only for isoviscous rheology. To accurately model the stress dependence of viscosity it is essential to resolve this stress singularity numerically. We will show in Appendix A that a minor modification of the prescription of the boundary condition at the corner point allows for accurate numerical simulation of the analytical cornerflow solution for isoviscous wedge rheology. In addition, it strongly reduces the impact of the stress singularity in the case of non-Newtonian rheology.

[10] Our base model closely follows the physical description for the Honshu model of PW99 with nearly identical subduction geometry except that for the top of the slab we use a cubic spline, rather than a piecewise linear function, to allow for smooth interpolation of the temperature field. The slab velocity is kinematically described and the wedge flow is assumed to be induced only by the downward flow of the slab. We do not allow flow in the 
tip of the wedge to a depth of $70 \mathrm{~km}$ (Figure 1) to better satisfy the Honshu heat flow data.

[11] To evaluate the wedge flow we solve the equations for mass and momentum conservation for an incompressible Boussinesq fluid:

$$
\begin{gathered}
\nabla \cdot \mathbf{v}=0 \\
\nabla \cdot(\eta \dot{\epsilon})-\nabla P=\mathbf{0}
\end{gathered}
$$

where $\mathbf{v}$ is velocity, $\eta$ is viscosity, $\dot{\epsilon}$ is the strain rate tensor, and $P$ is dynamic pressure. The velocity in the slab that drives the flow is tangent to the slabwedge interface and has a constant speed $V=91$ $\mathrm{mm} / \mathrm{yr}$. The top boundary of the wedge is formed by the bottom of the rigid portion of the overriding plate. The right hand side of the wedge is treated as an inflow/outflow boundary.

[12] After the velocity field for the wedge has been determined we solve the steady state heat equation for the entire grid

$$
\rho c_{p}(\mathbf{v} \cdot \nabla) T=\nabla \cdot(k \nabla T)+Q+Q_{s h}
$$

where $\rho$ is density, $c_{p}$ is heat capacity, $T$ is temperature, $k$ is the thermal conductivity and $Q$ is the internal heating rate caused by radiogenic elements. We also prescribe a shear heating rate $Q_{s h}$ along the plate interface to a depth of $70 \mathrm{~km}$. We assume that the shear heating is dominated by the strong deformation along the fault that separates the slab from the overriding plate. We do not incorporate volumetric shear heating. The rate of shear heating along the fault is given by the product of shear stress $\tau$ and downdip velocity $V$ with units $\mathrm{W} / \mathrm{m}^{2}$. We incorporate this in the heat equation by a function $Q_{s h}=\tau V \delta\left(x_{\text {interface }}\right)$ such that

$$
\int Q_{s h} d \Omega=\tau V
$$

The $\delta$ function has dimension $\mathrm{m}^{-1}$ with the property

$$
\int \delta\left(x_{\text {interface }}\right) d \Omega=1
$$

and $x_{\text {interface }}$ is the location of the plate interface. This integral property guarantees the correct dimension of $\mathrm{W} / \mathrm{m}^{3}$ for $Q_{s h}$ in (5). We follow general practice by treating $\tau$ as a free parameter and find the value that best corresponds with the observed heat flow in the forearc region.

[13] The slab has a thickness of $95 \mathrm{~km}$ and we assume that the mantle temperature at the base of the subducting slab is constant at $1450^{\circ} \mathrm{C}$. This is a simplification since we can predict that the temperature at the base of the slab changes slightly by diffusion. We nevertheless expect that this will have negligible effects on the temperature at the top of the slab because of the thickness of the slab.

[14] The boundary condition for temperature at the inflow boundary is given by an oceanic geotherm for $130 \mathrm{Myr}$ old lithosphere [Stein and Stein, 1992]. We also set the temperature at the wedge boundary at $95 \mathrm{~km}$ depth to $1450^{\circ} \mathrm{C}$ and we prescribe a geotherm from this depth to the surface that is consistent with the heat production and thermal conductivity of the overriding plate. Below $95 \mathrm{~km}$ depth, we treat the boundary as an outflow boundary condition.

[15] We use values for the parameters in the governing equations that are similar to those used by PW99. We use constant values for density $\rho=$ $3300 \mathrm{~kg} / \mathrm{m}^{3}$ and specific heat $c_{p}=1250 \mathrm{~J} / \mathrm{kg} \mathrm{K}$. The overriding plate is continental and we set radiogenic heating $Q$ to be $1.3 \mu \mathrm{W} / \mathrm{m}^{3}$ in the upper crust (to $15 \mathrm{~km}$ depth), $0.27 \mu \mathrm{W} / \mathrm{m}^{3}$ in the lower crust (between 15 and $30 \mathrm{~km}$ depth). Radiogenic heating is 0 everywhere else. The thermal conductivity $k$ is $2.5 \mathrm{~W} / \mathrm{m} / \mathrm{K}$ in the crust and $3.1 \mathrm{~W} / \mathrm{m} / \mathrm{K}$ in the mantle of the model. We vary the rate of shear heating rate $\tau V$ between 0 and $0.116 \mathrm{~W} / \mathrm{m}^{2}$. For the wedge, we assume either an isoviscous rheology or a temperature- and strain rate-dependent viscosity based on the dislocation creep law for dry olivine of Karato and Wu [1993]

$$
\eta(T, \dot{\epsilon})=A^{-1 / n} \mu \exp [E / n R T] \dot{\epsilon}^{(1-n) / n}
$$

where $A$ is a constant, $\mu$ the shear modulus, $E$ the thermal activation energy, $n$ the stress exponent, and $R$ the gas constant. Following Karato and $W u$ [1993] we use A $=3.5 \times 10^{22} \mathrm{~s}^{-1}, \mu=80 \mathrm{GPa}, E=$ $540 \mathrm{~kJ} / \mathrm{mol}$ and $n=3.5$. 
[16] In Appendix A we discuss the numerical implementation in detail. It is important to note that we use finite element models that have an order of magnitude higher resolution than most previously published models (see the summary in the work of Peacock [1996]). This allows us to accurately determine the temperature within the subducting crust and mantle.

\section{Results}

[17] The results for our Honshu model with isoviscous rheology are shown in Figure 2. The heat flow computed in our model with five different shear heating rates $\tau V$ between 0 and $116 \mathrm{~mW} / \mathrm{m}^{2}$ is compared with the observed heat flow values [Furukawa and Uyeda, 1989]. Our preferred model has a shear heating rate of $29 \mathrm{~mW} / \mathrm{m}^{2}$ since it provides the best fit to the heat flow data in the forearc region. This corresponds to an effective shear stress of $10 \mathrm{MPa}$. The heat flow comparison in the forearc region confirms the conclusion from PW99 that only a moderate amount of shear heating is required along the plate interface. The temperature in the slab, wedge and overriding plate for our preferred model is displayed in Figure 2b, with a close-up on the temperature (Figure $2 c$ ) and numerical grid (Figure 2d) in the tip of the wedge. The solid lines in the temperature plots correspond to the boundaries that define the grid (Figure 2d). The lower diagonal line in Figure 2c corresponds to a depth of $7 \mathrm{~km}$ below the slab-wedge interface.

[18] Our model does not include melt generation or the effects of magma migration and as a consequence we underpredict the heat flow values in the arc region. The temperature distribution in the slab shows rapid warming of the topmost crust, but a significant low temperature core persists in the slab because of the high subduction velocity. The resulting temperature gradient within the top of the subducting slab is significant at approximately $60 \mathrm{~K} / \mathrm{km}$.

[19] The same model with non-Newtonian olivine rheology (6) in the wedge is shown in Figure 3. The viscosity and stream function are compared for the isoviscous and non-Newtonian case in Figure 4. The main difference is the strong focus- ing of flow (compare Figure 4a with Figure 4b) into the wedge corner because of the lower viscosity. This effect was also observed by Furukawa [1993] using a Newtonian temperature-dependent rheology. Compared to the isoviscous model the temperature in the wedge is significantly increased, with resulting higher heat flow near the arc region. The heat flow in the forearc is not affected by the changes in the wedge rheology.

[20] To investigate the potential of water transport into the deep mantle we compare the predicted temperature with the phase diagrams for hydrated basalt (corresponding to subducting oceanic crust) and hydrated lherzolite (representing the upper mantle). The phase diagram for basalt (Figure 5a) is based on the work of Poli and Schmidt [1995]. The PT conditions along the base of the oceanic crust (which is assumed to have a constant thickness of $7 \mathrm{~km}$ ) and along the slab-wedge interface are compared in Figure $5 \mathrm{~b}$ to the previous results by PW99 (a1, a2: black lines). The green lines (b1, b2) correspond to the calculation with isoviscous rheology (Figure 2) and the red lines (c1, c2) are based on the model with non-Newtonian rheology (Figure 3). The phase diagram for lherzolite and water (Figure 5c) is based on the work of Schmidt and Poli [1998] with a modification for the $10 \AA$ phase as in the work of Fumagalli et al. [2001]. Figure $5 \mathrm{~d}$ shows the temperatures at the Moho of the subducting slab for the three models.

[21] For the Honshu subduction zone, the rapid convergence leads to very strong temperature gradients across the subducting crust (Figure 5b). Conduction of heat through the crust is relatively slow and the base of the crust remains cool to the maximum depth of the model. In contrast, the top of the crust experiences high temperatures as soon as it is brought into contact with the hot wedge, with the potential for melting in the topmost crust, in particular for the model with the non-Newtonian wedge rheology.

[22] As is shown in Appendix A, the main difference between the isoviscous model (curves b1 and b2) and the model from PW99 (curves a1 and a2) lies in the prescription of the cornerflow. In PW99, a modification of the analytical cornerflow solution 

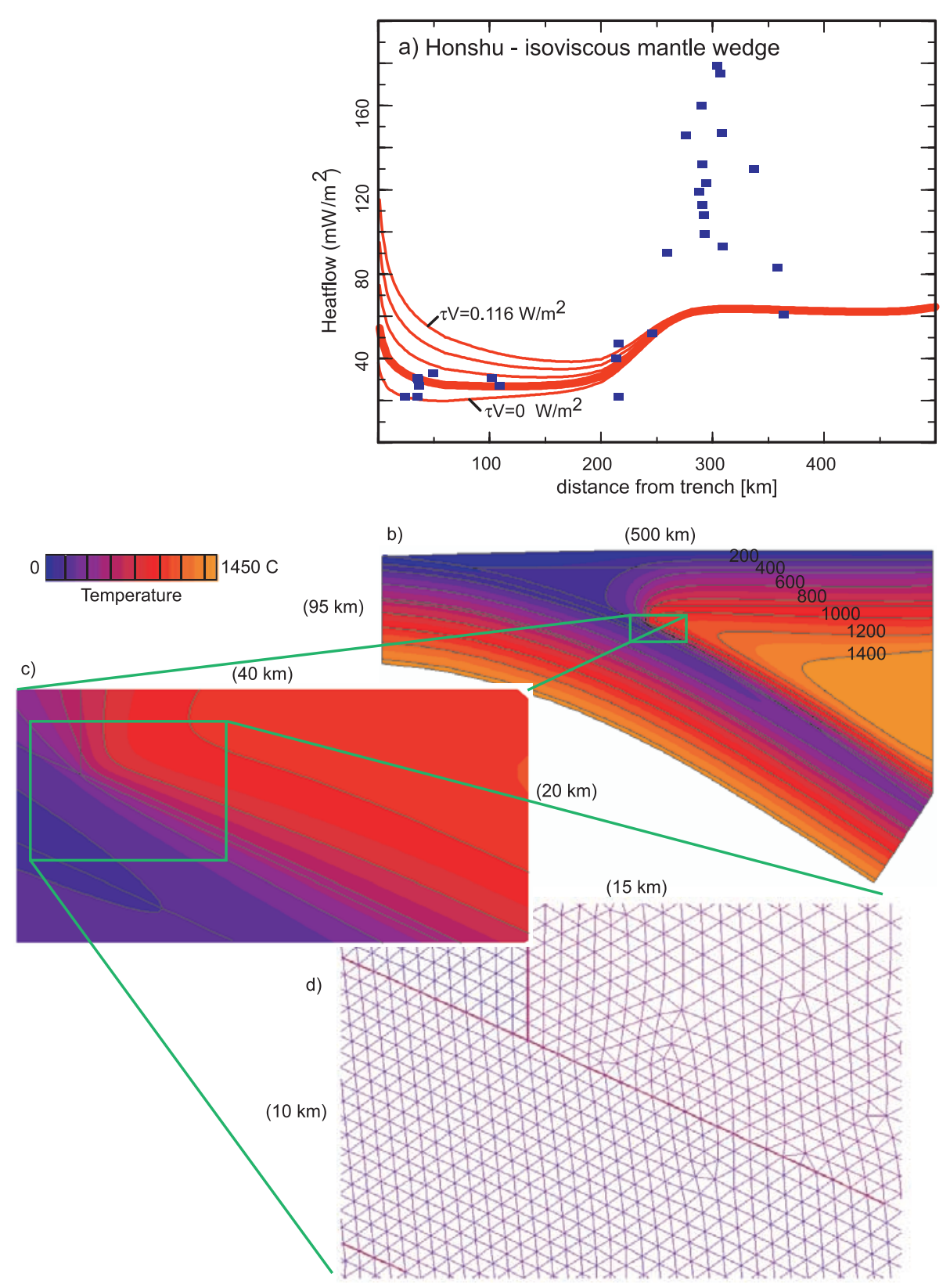

Figure 2. Results for the Honshu model assuming an isoviscous mantle wedge. (a) Computed heat flow is compared with local heat flow measurements [Furukawa and Uyeda, 1989]. We used five different values for shear heating rates of $0,29, \ldots, 116 \mathrm{~mW} / \mathrm{m}^{2}$. The heat flow for our preferred case with $\tau V=29 \mathrm{~mW} / \mathrm{m}^{2}$ is shown in bold. (b) Computed temperature for our preferred case. Note the strong increase of temperature along the slab-wedge interface and the persistence of low temperatures in the core of the subducting slab. (c) Close-up of the temperature in the cornerflow region. (d) Further close-up of the mesh in this region. The average grid spacing is approximately $400 \mathrm{~m}$.

of Batchelor [1967] is used in which the velocity in the toe of the wedge is set equal to zero. This is a numerically convenient, but physically somewhat crude approximation. In this paper, we specify a more appropriate physical boundary conditions for zero flow in the wedge. This leads to a strong focusing of the downward flow in the wedge in contrast to the more diffusive transport in PW99. As a consequence, the temperature at the top of the slab is significantly higher in the new simulation.

[23] The presence of the strong temperature gradient, which is well resolved by the dense numerical grid, leads to two important implications for the 

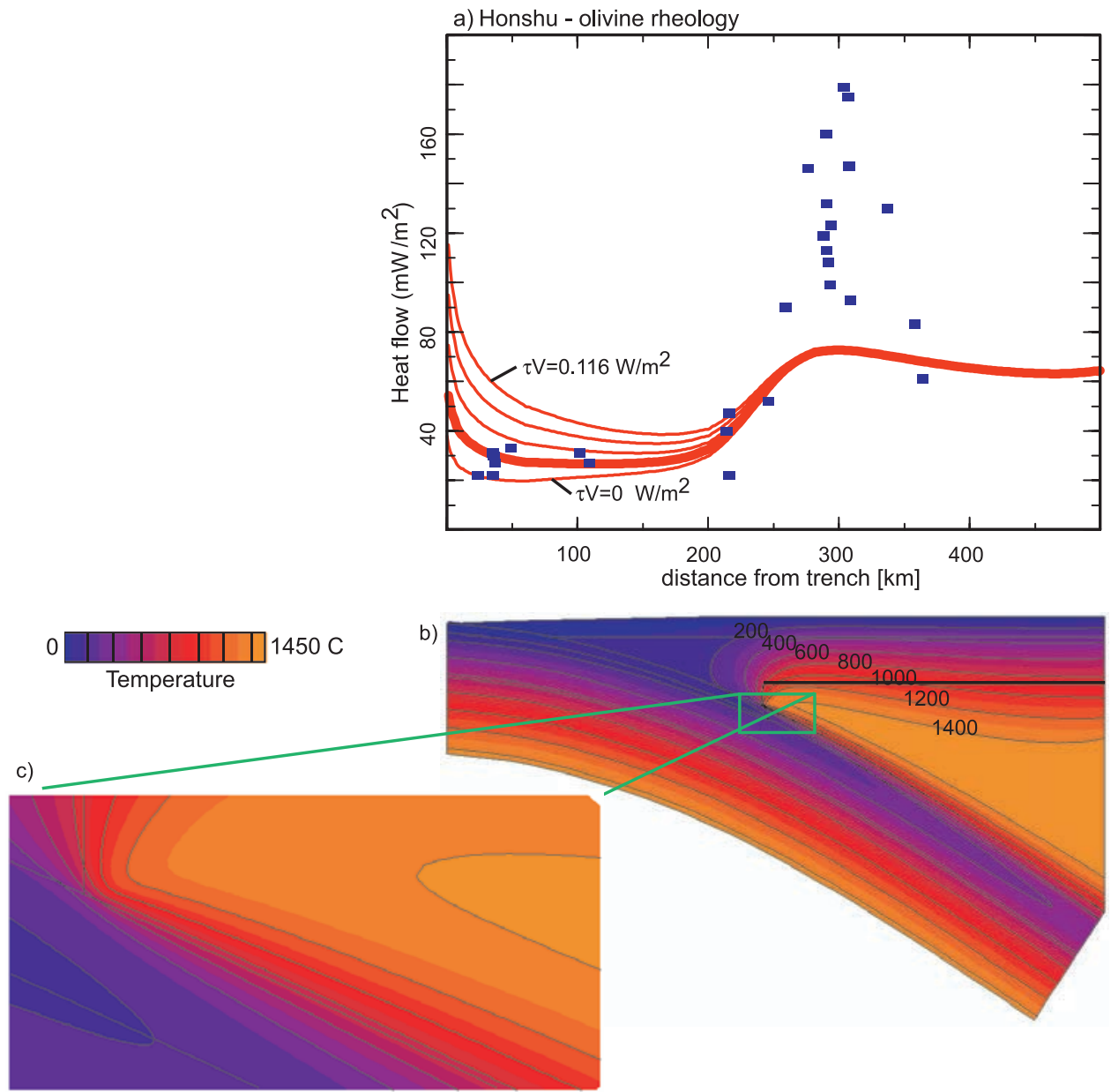

Figure 3. Results for the Honshu model assuming an olivine rheology for the mantle wedge. Same as Figures $2 \mathrm{a}-$ $2 \mathrm{c}$, except with a stress- and temperature-dependent rheology in the mantle wedge. Note the strong elevation of wedge temperature in the cornerflow region because of the variable rheology.

interpretation of arc geochemistry and for the transport of water to the deep mantle. First, the slab PT curves in Figure 5 suggest that it is possible to achieve high temperature at the very top of the subducting oceanic crust and sediment section, while low temperatures persist through the middle and lower crust. This provides an intriguing resolution for the differences in slab temperature estimates based on $\mathrm{Be}$ and Th data on the one hand, and $\mathrm{B}$ data on the other. Both estimates may correctly image the local thermal conditions, but they represent two different depth levels in the subducting lithosphere. The Be and Th data reflect high temperatures in the subducting sediments, whereas the $\mathrm{B}$ data reflect cooler dehydration in the underlying shallow altered oceanic crust, consistent with the suggestion that B in volcanic arcs is predominantly derived from altered oceanic crust [Ishikawa and Nakamura, 1994; Smith et al., 1997].

[24] Second, the strong temperature gradient provides the means to recycle water into the deeper mantle in the basaltic and ultramafic sections of the slab [e.g., Ito et al., 1983; Peacock, 1990, 2001; Bebout, 1996]. The amount and transport mechanism depend critically on the water distribution in the subducting slab. Hydrothermal alteration in oceanic crust is variable with depth but occurs in the lavas, sheeted dikes and topmost gabbros to at least $2 \mathrm{~km}$ depth [Dick et al., 2000; Alt and Teagle, 2000]. Hydration may occur deeper in the oceanic crust, and potentially the top most upper mantle, along localized faults and fracture zones [e.g., Krawczyk et al., 1996] or near ridges where the 


\section{Comparison of stream function with isoviscous and non-Newtonian rheology}

a) isoviscous

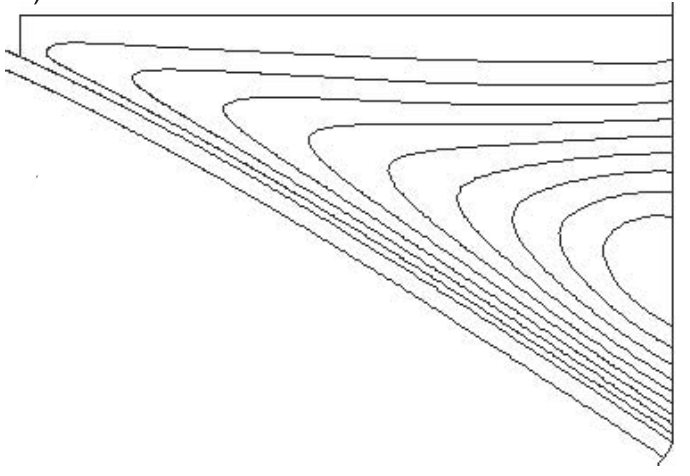

b) non-Newtonian

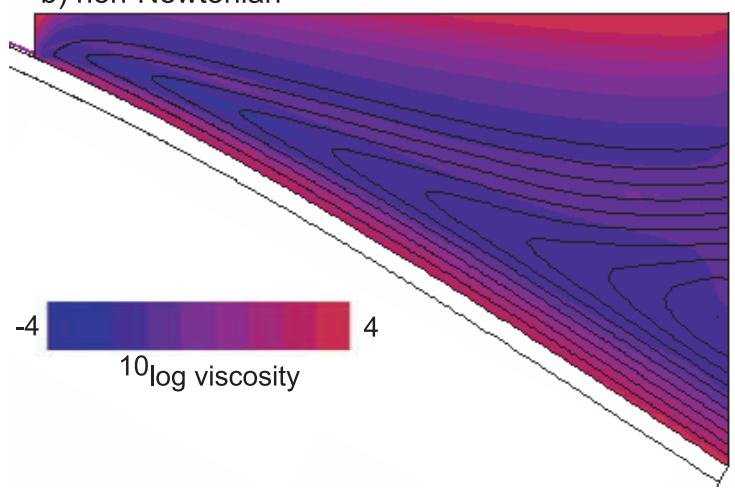

Figure 4. Viscosity and stream function in the wedge for the isoviscous (frame a) and non-Newtonian (frame b) Honshu model. The strong increase in temperature is caused by channeling of the flow due to the temperature- and strain rate-dependent viscosity. The stream function for the isoviscous case shows a more diffuse pattern of flow.

peridotite upper mantle is in direct contact with seawater [Seifert and Brunotte, 1996].

[25] Our models suggest that hydrated portions of the slab remain cool enough to allow for the presence of hydrous phases and that water can be transported into the deep mantle both in the subducted crust (Figure 5a) and potentially in the uppermost mantle of the subducting slab (Figure 5b). These predictions are consistent with seismological observations that indicate the presence of hydrated crust in the north Pacific subduction zones [Helffrich, 1996; Abers, 2000]. Our findings support earlier suggestions that deep subduction of crystallographically bound water is possible either in the basalt [e.g., Pawley and Holloway, 1993; Peacock, 1996; Schmidt and Poli, 1998; PW99] or upper mantle portion of the subducting slab [Thompson, 1992; Ulmer and Trommsdorff, 1995; Peacock, 2001].

[26] In order to determine if our predictions for the potential for survival of hydrous phases are generic for the Earth's subduction zones or linked particularly to old and fast subduction zones such as Honshu, we use our model to evaluate the thermal structure of a young and moderately fast subduc- tion zone with conditions similar to Cascadia. In this case we use a similar grid as in the Honshu model, but now with a larger subduction angle of $60^{\circ}$ at depth, as suggested by the tomographic results of Bostock and VanDecar [1995, profile $\mathrm{AB}$, Figure 7]. The age of the subducting lithosphere is $10 \mathrm{Myr}$ at the trench. We also take into account a $3 \mathrm{~km}$ thick sediment cover at the trench that we assume to be scraped off to form the accretionary wedge. The slab subducts at a constant speed of $45 \mathrm{~mm} / \mathrm{yr}$.

[27] Figure 6 shows the temperature distribution calculated for these parameters using an olivine rheology in the wedge. We compare the predicted heat flow values for the same range of shear heating as before (Figure 6a) with heat flow values from the work of Hyndman and Wang [1995]. Note that these are along a profile that is slightly to the north of that of the profile of Bostock and VanDecar [1995]. The comparison suggests that shear heating is relatively unimportant for the Cascadia subduction zone, which is consistent with previous work [Hyndman and Wang, 1995]. This also suggests that volumetric shear heating is unimportant, at least in the 
a) Water saturated basalt

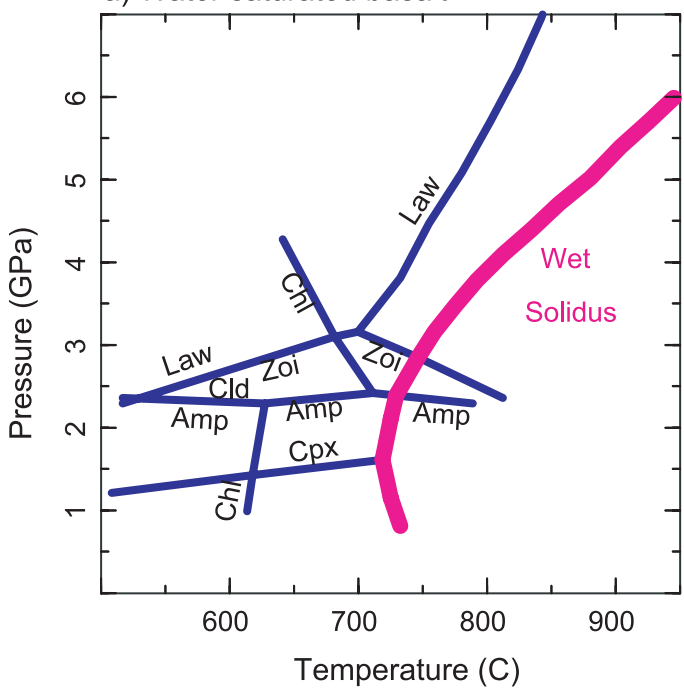

c) Lherzolite + water

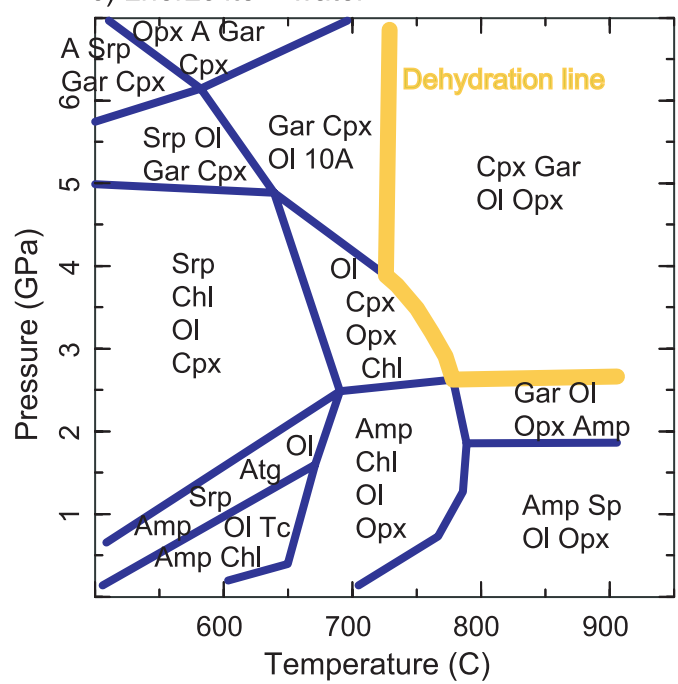

b)

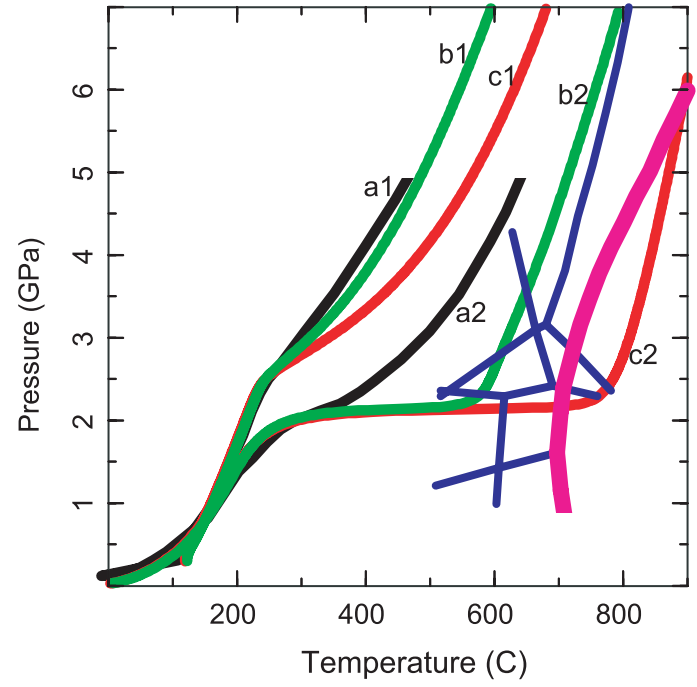

d)

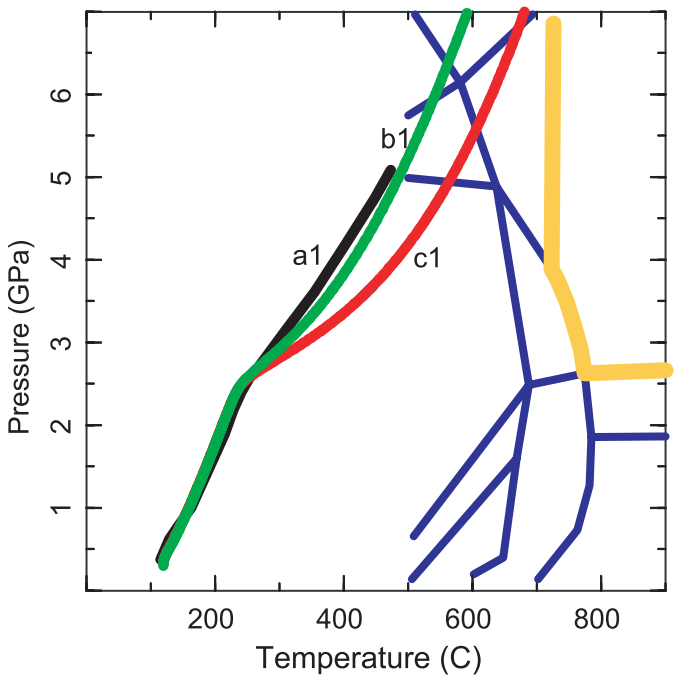

Figure 5. Phase assemblages and predicted pressure-temperature paths at the slab-wedge interface and at $7 \mathrm{~km}$ depth into the slab. The PT paths are based on the computations of PW99 (black curves), isoviscous calculations (as in Figure 2; green curves), and non-Newtonian calculations (as in Figure 3; red curves), all after the a posteriori addition of an adiabatic gradient of $0.5 \mathrm{~K} / \mathrm{km}$. (a) Phase diagram showing stable hydrous minerals in water-saturated basalt [Poli and Schmidt, 1995]. Amp = amphibole, $\mathrm{Chd}=$ chloritoid, $\mathrm{Chl}=$ chlorite, $\mathrm{Cpx}=$ clinopyroxene, $\mathrm{Law}=$ lawsonite, Zoi = zoisite. (b) Pressure-temperature path of subducted oceanic crust plotted on the phase diagram for water-saturated basalt. a1,a2 = PW99, b1,b2 = isoviscous, and c1,c2 = stress- and temperature-dependent viscosity. For each of these pairs, the first curve is at the base of the oceanic crust at $7 \mathrm{~km}$ depth (a1, b1, and c1) and the second (hotter) curve (a2, b2, and c2) is at the top of the crust. (c) Phase diagram showing hydrous minerals the system lherzolite + water [Schmidt and Poli, 1998]. The high-pressure extension of the dehydration line is from the work of Fumagalli et al. [2001]. $\mathrm{A}=$ phase $\mathrm{A}, 10 \mathrm{~A}=10 \AA$ phase, $\mathrm{Amp}=$ amphibole, $\mathrm{Atg}=$ antigorite, $\mathrm{Chl}=$ chlorite, $\mathrm{Cpx}=$ clinopyroxene, $\mathrm{Gar}=$ garnet, $\mathrm{Ol}=$ olivine, $\mathrm{Opx}=$ orthopyroxene, $\mathrm{Sp}=$ spinel, $\mathrm{Srp}=$ serpentine, $\mathrm{Tc}=$ talc. $(\mathrm{d})$ Pressure-temperature path at $7 \mathrm{~km}$ depth into the slab. Same as in (b).

forearc region, since any addition by volumetric shear heating would increase the heat flow and this would lead to a poor fit to the observed heat flow values.
[28] The lower convergence velocity and much younger age of the incoming lithosphere lead to substantially different conditions at depth (Figure 7) compared to the older and faster Honshu subduc- 
a) Cascadia - olivine wedge rheology

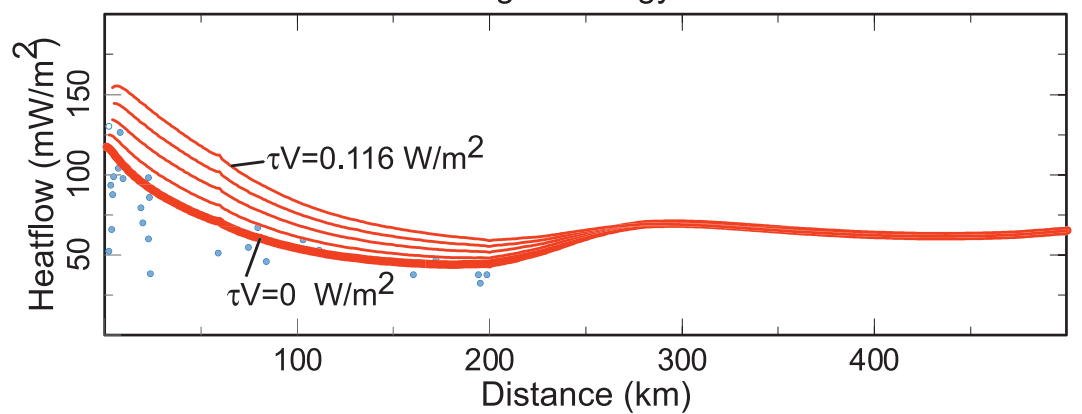

b)

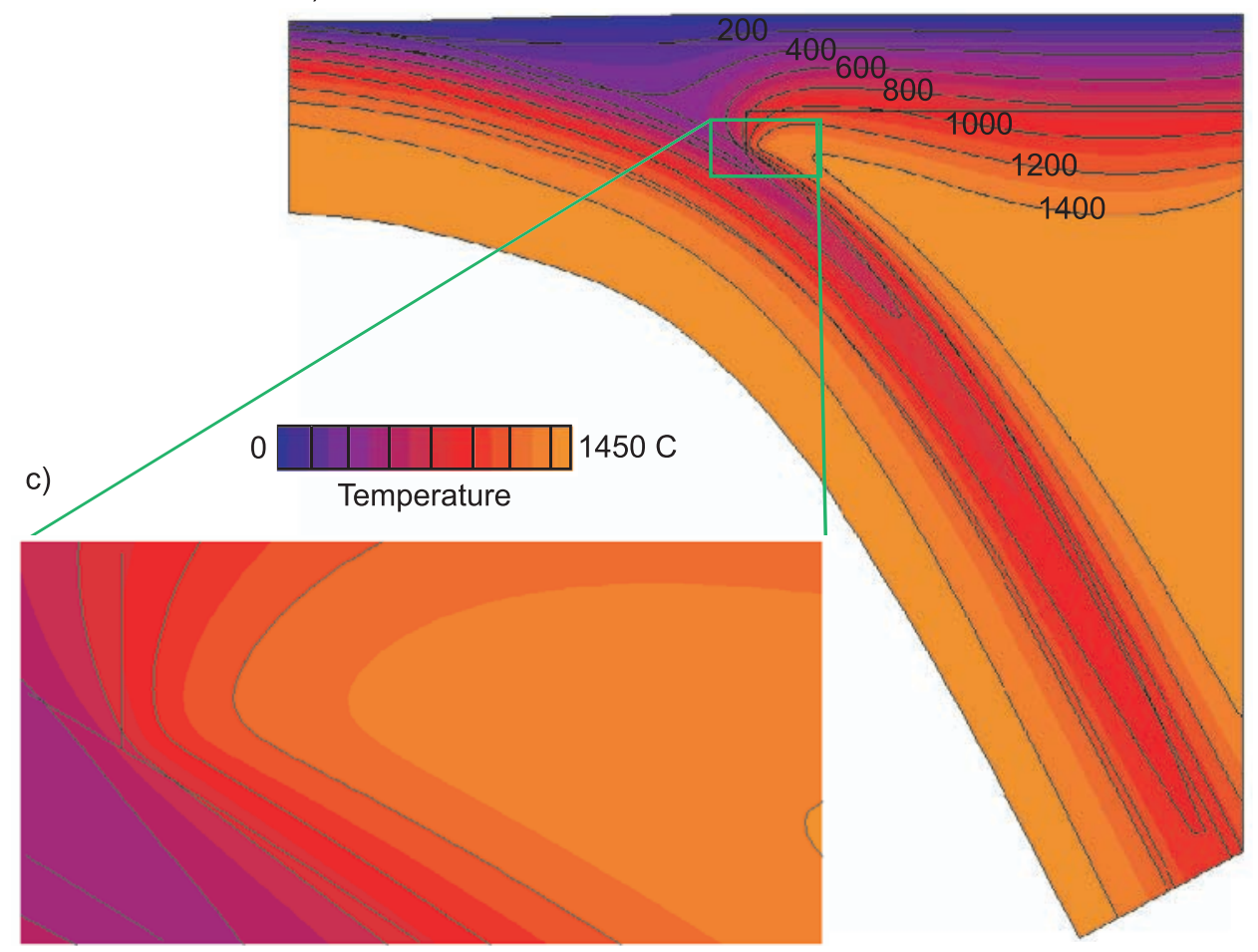

Figure 6. Steady state temperature solution for a model with characteristics similar to that of the Cascadia subduction zone. The mantle wedge flow is established with olivine rheology. The differences with the Honshu model in Figure 3 include the lower convergence rate $(45 \mathrm{~mm} / \mathrm{yr})$, younger age of oceanic lithosphere at the trench (10 Myr), the inclusion of a $3 \mathrm{~km}$ thick sediment package above the incoming lithosphere, and greater dip of the subduction zone at depth. We assume that the sediment package is scraped off at the trench to form the accretionary prism. We find substantially higher temperatures and heat flow values in the forearc and higher temperatures in the subducting crust and upper mantle.

tion zone. Temperatures are significantly higher and exceed the wet solidus by more than $300^{\circ} \mathrm{C}$ in the wedge corner. The temperature at the base of the crust is also substantially hotter, which leads to the prediction that most of the hydrated portions of the basaltic crust can be partially molten (Figure 7a) and that the top of the subducting mantle (Figure $7 b$ ) can be completely dehydrated in the Cascadia subduction zone. Note that we do not take the latent heat effects of melting or secondary phase changes into account and our PT curves are therefore a maximum estimate of the expected temperatures at depth.

\section{Discussion}

[29] The main purpose of this paper is to investigate how the interpretation of previously pub- 
a) Water saturated basalt

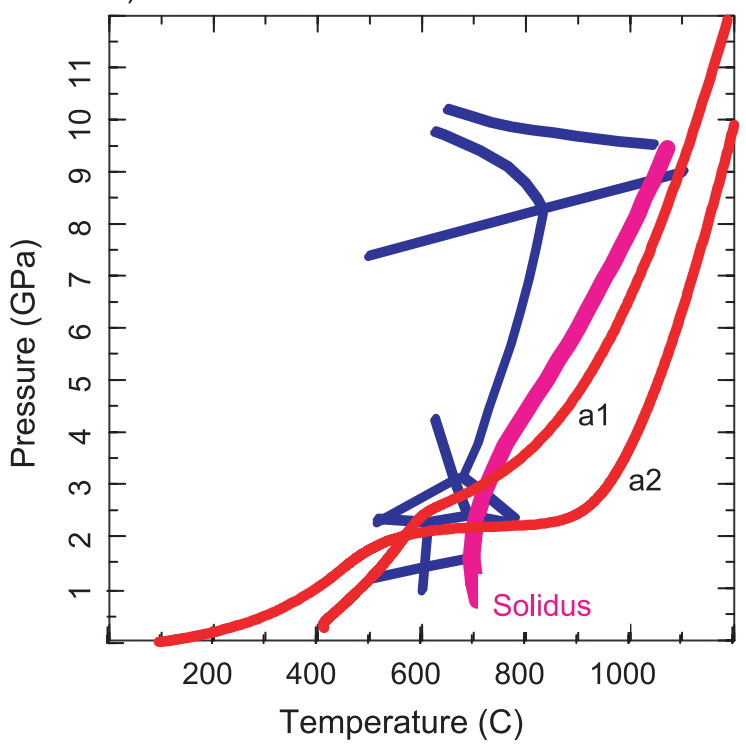

b) Lherzolite + water

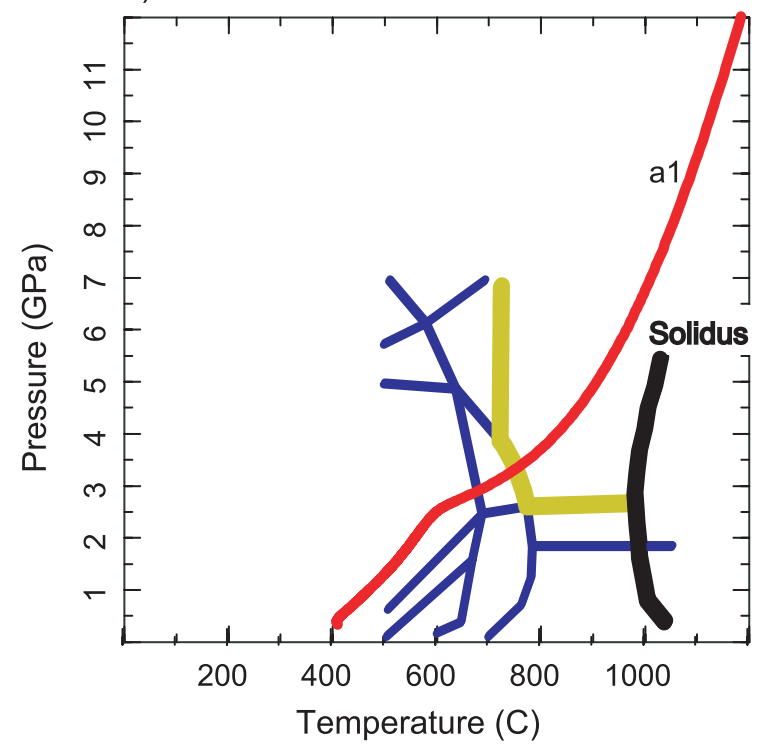

Figure 7. Comparison of the PT curves at the base (curve a1) and top of the subducting oceanic crust (curve a2) with phase diagrams for water-saturated basalt (panel a) and hydrated lherzolite (panel b). This model predicts that the entire subducting crust may undergo partial melting. The high temperatures throughout the subducting slab would cause widespread, if not complete, dehydration, including the upper mantle portion of the subducting slab.

lished subduction zone models changes with the use of a more realistic olivine rheology and higher grid resolution. These modifications are only two of the steps needed to generate more realistic models of the dynamics and thermal structure of subduction zones and it is important to view our findings within this context. The most important changes we find are (1) temperature- and stressdependent rheology allows for a focusing of the return flow which leads to significantly higher temperatures in the corner flow region compared to isoviscous rheology; and (2) in the case of fast subduction of old lithosphere a strong thermal gradient develops across the subducting oceanic crust that persists to great depth.

[30] We have focused in this paper on two modern subduction zones. This allows for direct comparison with geophysical and geochemical observations in these geographic regions. It is nevertheless reasonable to question how robust our conclusions are in the light of the variability of subduction zone parameters such as age, speed, shear heating etc. For this purpose, we have performed an extensive set of comparisons that are summarized in Appendix B. There we show that our first conclusion, namely that incorporating realistic rheology leads to a significant increase of slab interface temperature, is very robust. In all cases, we find an increase of slab interface temperature at $3 \mathrm{GPa}$ of $150-225^{\circ} \mathrm{C}$ for non-Newtonian as compared to isoviscous mantle wedge rheology. In regard to the second conclusion, the Honshu and Cascadia subduction zones are endmembers in terms of subduction zone parameters (old and fast versus slow and hot) and as expected the predictions for dehydration and melting for intermediate cases lie in between these two extremes.

[31] Further improvements that are necessary include a better understanding of the rheology and geometry of the subduction zone and the influence of dehydration and melting. For example, this paper illustrates the important role of wedge rheology, by using a dry olivine dislocation creep law. It is important to understand how fluid and magma flow through the wedge influences the rheology [Karato, 2002] and subsequently the thermal structure and dynamics of the slab and wedge. In general, we would expect weakening of the wedge by fluid flow, which has the potential for strengthening the focusing wedge flow even 
further and for even higher temperatures in the wedge.

[32] This study also confirms the importance of the correct description of the geometry and physics of the subduction zone. The model results are quite sensitive to relatively minor changes in prescription of the cornerflow. Of particular interest for future studies are the physics and depth extent of the coupling along the plate interface, the rheology and geometry of the transition to ductile flow, and the role of weaker lithologies at the top of the subducting slab. It is quite possible that the shear can be accommodated completely along a narrow shear zone [e.g., Yuen et al., 1978] which would lead to much reduced traction along the base of the mantle wedge. The further investigation will require better insights from seismology and mineral physics, supported by forward modeling using high-resolution approaches such as the finite element models presented here.

\section{Conclusions}

[33] We have improved existing models of the thermal structure of the Honshu and Cascadia subduction zones by using a very high-resolution finite element method and realistic olivine rheology in the mantle wedge. In comparison to isoviscous wedge rheology we find that the temperatures in the cornerflow region are enhanced by several hundreds of degrees, which generates high temperatures at the slab-wedge interface. This is a robust conclusion for a wide range of physical parameters including the age of the incoming lithosphere, shear heating, dip angle, and velocity. With the high-resolution grid, we can resolve strong thermal gradients in the crust and mantle of the subducting slab in the case of fast subduction of old lithosphere beneath Honshu. The strong temperature gradient allows for a reconciliation of the geochemical evidence for high temperatures based on Th, Be evidence for sediment melting and substantially lower temperatures based on B evidence for mineral dehydration, by assuming that the $\mathrm{B}$ is released from the cooler portions of the subducting oceanic crust. The temperatures in the crust and upper mantle of the subducting slab are sufficiently low to allow for water transport to the deep mantle. A comparison with the thermal structure predicted for the slow subduction of young lithosphere at Cascadia suggests widespread partial melting of the subducted sediments and crust, and predicts strong if not complete dehydration of the subducting slab.

\section{Appendix A: Numerical Implementation, Convergence Tests, and a Method to Resolve the Stress Singularity in the Numerical Corner Flow Models}

[34] Equations (1)-(3) are solved numerically using a finite element approach based on the commercial package Sepran [Cuvelier et al., 1986; http://dutita0.twi.tudelft.nl/sepran/sepran. html]. The finite element approach allows for flexible and accurate discretization of the grid. We use a special line element approach for the shear heating at the plate interface (equation (4)) by explicit implementation of the $\delta$ function. This guarantees that the shear heating only takes place along the plate interface. We use a variable and locally very high-resolution discretization of the computational domain using linear triangles. High resolution is imposed throughout the wedge and in particular in the cornerflow region, as well as at the surface (to allow for accurate heat flow calculations) and around the plate interface (for accurate evaluation of the impact of the shear heating term). In these regions the distance between neighboring nodal points is approx. 400 meters (see Figure 2c), which is an order of magnitude higher resolution than most previous studies that incorporated variable wedge rheology (see the summary in the work of Peacock [1996]). The resulting grid has close to 75,000 elements and 37,000 nodal points.

[35] For the solution of the Stokes equation combined with the incompressibility constraint ((1) and (2)) we use linear Taylor-Hood triangles. The velocity and pressure are found by a conjugate gradient iteration (BiCGSTAB) [Van der Vorst, 
a)

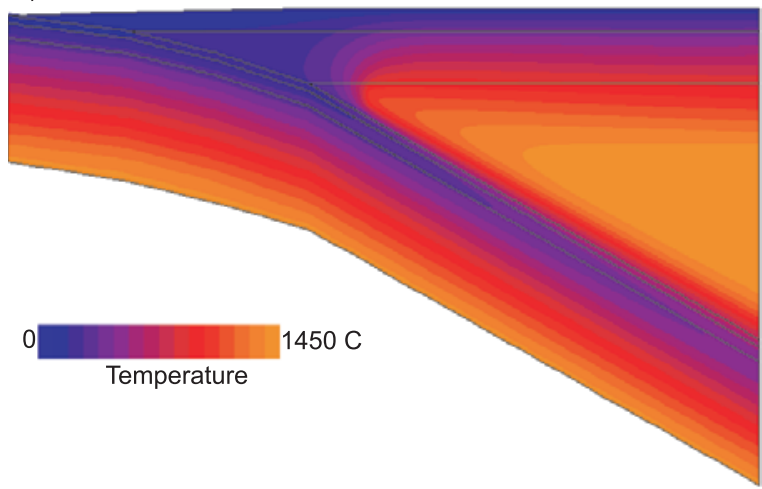

b)
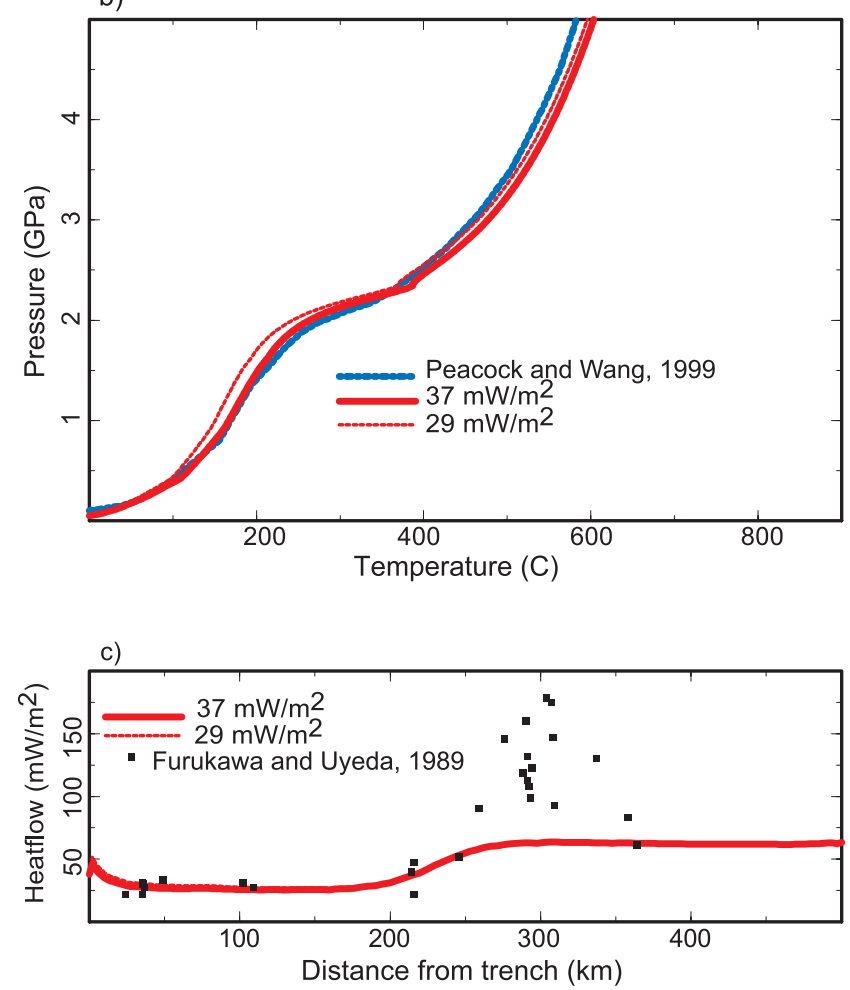

Figure A1. (a) Temperature field for the Honshu subduction zone based on a reevaluation of the model presented by Peacock and Wang [1999, Figure 2b], using our current finite element code. Main differences with the model in Figure 2 involve the treatment of the cornerflow in the wedge tip area. The analytical cornerflow solution of Batchelor [1967] is imposed, but velocities are set to zero in the triangular area indicated in Figures 1 and 2. Constant shear heating is imposed down to $70 \mathrm{~km}$ depth and the subducting slab is prescribed by piecewise linear segments. (b) Comparison of the predictions for the PT curve corresponding to the top of the subducting slab based on PW99 and the present model using two slightly different values for the shear heating rate. A somewhat better fit is obtained for the model with slightly higher shear heating rate along the fault. (c) Predicted heat flow (as in Figure 2a).

1992] after ILU preconditioning. The heat equation is solved in a similar manner after discretization using streamline upwinding. The solution is obtained with a residual of less than $10^{-8}\left(L_{\infty}\right.$ norm). When we use stress- and temperature- dependent rheology, the Stokes equation (2) becomes nonlinear and nonlinearly coupled with the heat equation (3). In that case, we use two iteration loops: an inner iteration for the Stokes equation in which the velocity and viscosity terms 


\section{a) Analytical cornerflow}

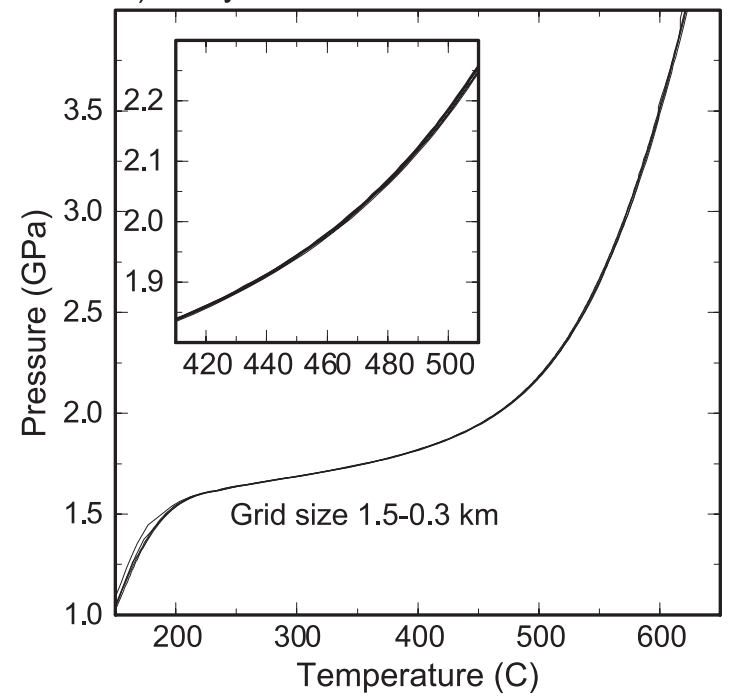

b) Finite element flow computation

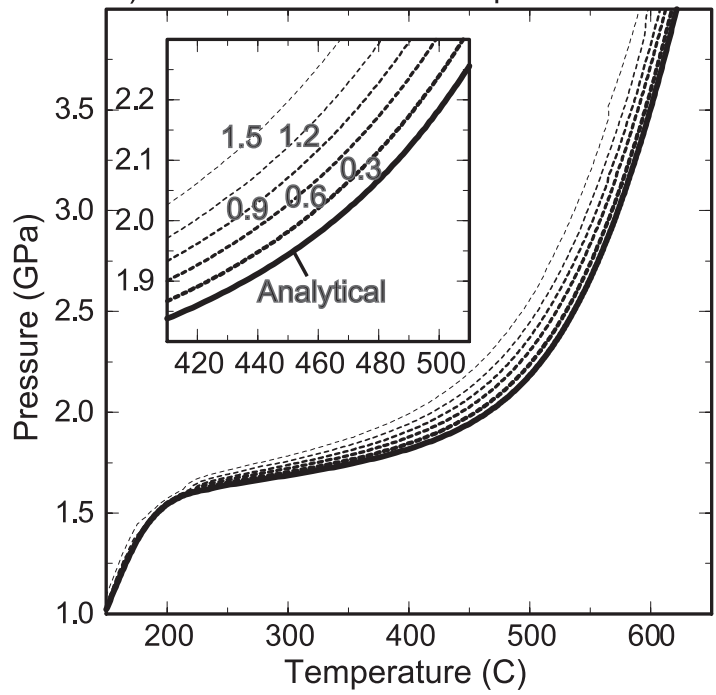

Figure A2. The singularity in the boundary conditions for the cornerflow at the wedge tip cause numerical inaccuracies if the flow is solved by standard finite element techniques. (a) Comparison of PT curve at the top of the slab computed with the full analytical Batchelor cornerflow solution (including the wedge tip) for increasing finite element resolution. The grid size varies from $300 \mathrm{~m}$ to $1.5 \mathrm{~km}$ in the cornerflow region. This comparison suggests that grids with $1 \mathrm{~km}$ or larger spacing provide sufficient resolution. (b) As in (a), but now with the cornerflow evaluated by the numerical solution of the Stokes and mass conservation equations (1) and (2). The singularity causes poor convergence behavior. This comparison suggests that grid spacing below $300 \mathrm{~m}$ should be used to find solutions that agree to within $10^{\circ} \mathrm{C}$ of the solution obtained with the analytical cornerflow solution.

are updated, and a global iteration on the Stokes and heat equations. The iteration is converged when the maximum relative difference between successive iteration of the velocity and temperature solutions is less than $10^{-6}$. When using the olivine rheology (6) about 15 global iterations are required to reach convergence.

[36] We performed extensive tests to determine the effect of grid resolution on the temperature solution. Calculations using a grid with twice the number of grid points shows less than $10^{\circ} \mathrm{C}$ difference along the slab-wedge interface.

[37] In order to test the accuracy of our finite element approach we performed a number of comparisons and convergence tests. Figure A1 shows our reevaluation of the PW99 Honshu model. The geometry and physical description are as close to PW99 as possible and we ascribe the (minor) differences in the solution to numerical resolution and accuracy. The temperature field (frame a) and PT curves (frame b) compare well with the PW99 model. A somewhat better fit to the PT curve is found at slightly higher shear heating along the plate interface, although this is barely distinguishable in the surface heat flow (frame c).

[38] The cornerflow in this model is imposed by a modification of the analytical cornerflow solution [Batchelor, 1967] by setting the velocities in the triangle $\mathrm{ABC}$ of Figure 1 to zero. This is a convenient, although physically not entirely consistent approach, that also helps to reduce the impact of the stress singularity that occurs in the wedge tip (point A in Figure 1) in the unmodified cornerflow solution. This singularity is caused by the discontinuity in the boundary conditions at A, where the slab boundary condition changes from free-slip to no-slip. This discontinuity remains present when the point at which the boundary condition changes is moved down the slab (as used by Furukawa [1993]) or when the triangular 
a) Grid size $0.3 \mathrm{~km}$

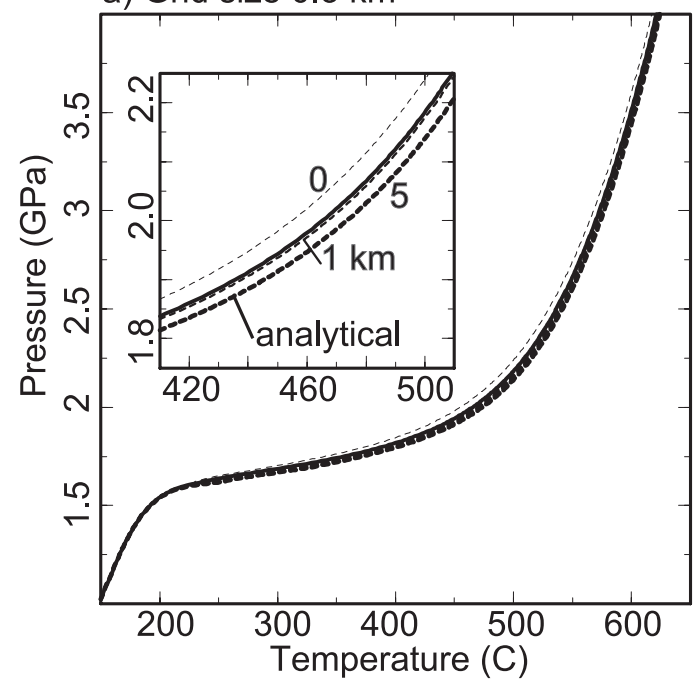

b) Grid size $0.6 \mathrm{~km}$

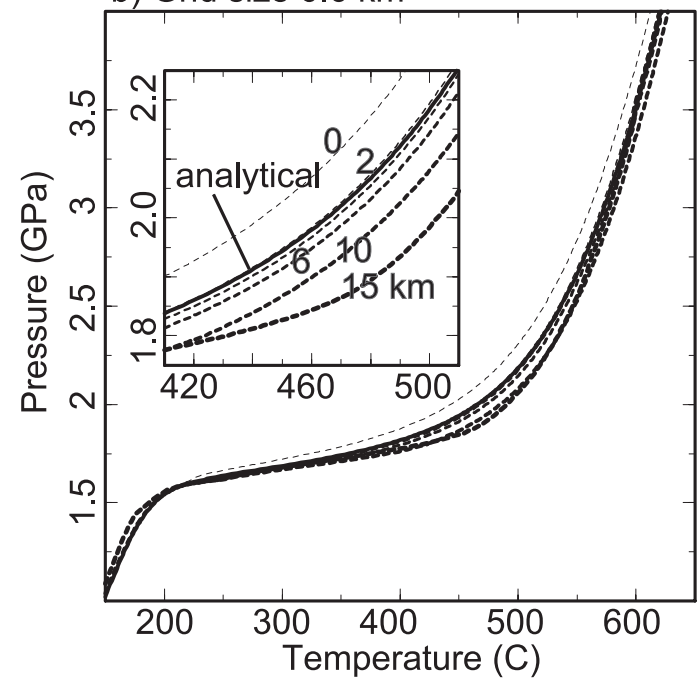

c) Grid size $1.5 \mathrm{~km}$

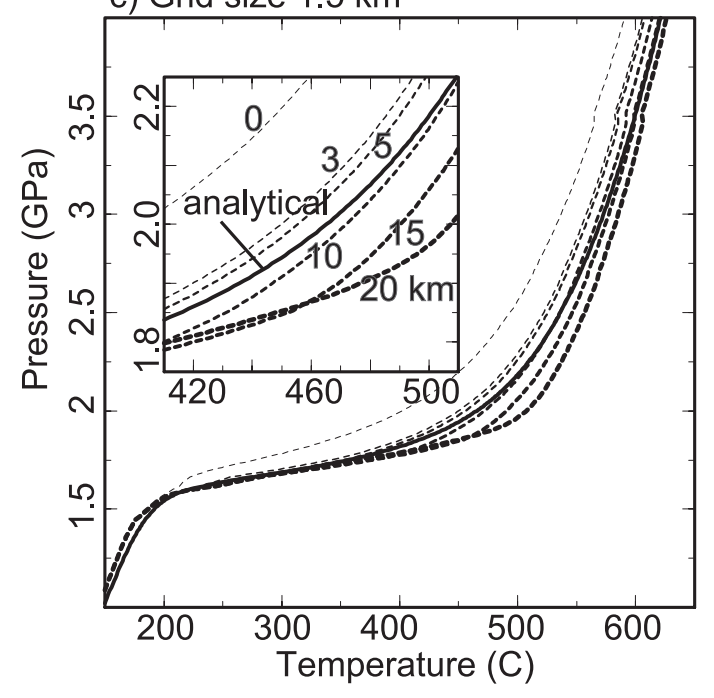

wedge tip is explicitly excluded from flow (as done in this paper).

[39] It is easy to show that the analytical solution is well behaved near the singularity and using the Batchelor solution itself leads to satisfactory results for the temperature field. Figure A2a shows the PT curve corresponding to the slab surface for increasing mesh resolution computed with the full (unmodified) Batchelor solution. The grid size indicates the typical element size in the cornerflow region (see also Figure 2d). The overlap of PT curves indicates convergence of the numerical solution for a grid resolution of $1 \mathrm{~km}$ or less.

[40] The numerical solution behaves less well when the cornerflow solution is established by numerical solution of the Stokes and mass conservation equations (1) and (2). The impact of the discontinuous boundary condition is seen in the poor convergence behavior of the temperature as shown in Figure A2b. Even at the highest resolution, the PT curve has not approached the solution obtained with the analytical cornerflow solution. This is a particular concern for models that require numerical solution of the corner flow, for example due to the presence of variable rheology or other physical properties in the mantle wedge.

[41] We found that a simple adjustment to the slab boundary condition leads to a more satisfactory behavior of the temperature solution. This involves smearing out the discontinuous change from free-slip to no-slip at the wedge tip by linearly increasing the amount of coupling between slab and wedge over a small distance. In practice, this is done by linearly increasing the

Figure A3. (opposite) The singularity in the boundary conditions can be smeared by a linear ramp over a small distance to provide much better convergence behavior. The comparison at grid size $300 \mathrm{~m}$ (a), $600 \mathrm{~m} \mathrm{(b),} \mathrm{and}$ $1.5 \mathrm{~km}$ (c) show that the smearing should take place over a distance that corresponds to approximately three elements. Particularly for the grids with elements smaller than $1 \mathrm{~km}$, a good correspondence with the analytical (Batchelor) cornerflow solution is found. 


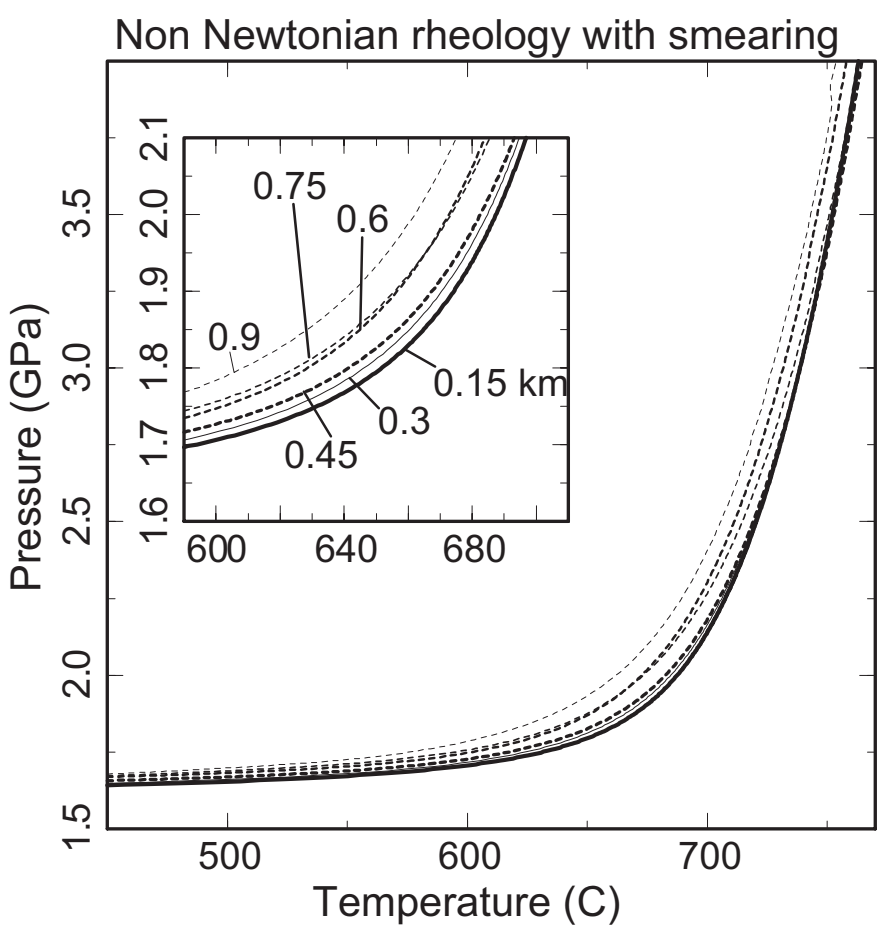

Figure A4. Convergence behavior of the model with non-Newtonian rheology.

imposed velocity from 0 at corner point to the full slab velocity. Figure A3 displays the PT curve obtained at three different grid resolutions (ranging from $300 \mathrm{~m}$ in frame a to $1.5 \mathrm{~km}$ in frame c) and for various lengths over which the change in boundary condition takes place (indicated by the small letters in the inset). The PT curves are compared to those obtained with the analytical cornerflow solution (solid lines indicated with "analytical"). This comparison shows that the smearing is effective at fine grids (less than 1 $\mathrm{km}$ resolution) and that, as a rule of thumb, the transition should take place over approximately three elements.

[42] Figure A4 shows the well behaved convergence behavior of the cornerflow solution using the smeared boundary condition with non-Newtonian olivine rheology (equation(6)). The simulation with $450 \mathrm{~m}$ grid size provides a solution to within $10^{\circ} \mathrm{C}$ from the highest-resolution case, which we consider sufficient precision. This shows that our minor modification of the slab boundary condition provides a satisfactory solution to the mathematical singularity in the corner point even for nonlinear rheology.

\section{Appendix B: Sensitivity of the Conclusions to Variations in the Subduction Zone Parameters}

[43] In this paper we focus on model simulations that use the physical description of two modern day subduction zones. To test the sensitivity of our conclusions to variations in the physical parameters we have computed the thermal structure for a large number of models in which we varied the age of the incoming lithosphere $(0-$ $100 \mathrm{Myr})$, subduction velocity $(0-10 \mathrm{~cm} / \mathrm{yr})$, dip of the slab $\left(30^{\circ}\right.$ and $\left.60^{\circ}\right)$ and the amount of shear heating $\left(0-36 \mathrm{~mW} / \mathrm{m}^{2}\right)$. Figure B1 shows the difference in temperature at the slab interface at $3 \mathrm{GPa}$ between models with constant and nonNewtonian wedge rheology (while keeping all other parameters constant). The upward shift in temperature that we observed for the Honshu subduction zone (compare Figure 5) is repro- 


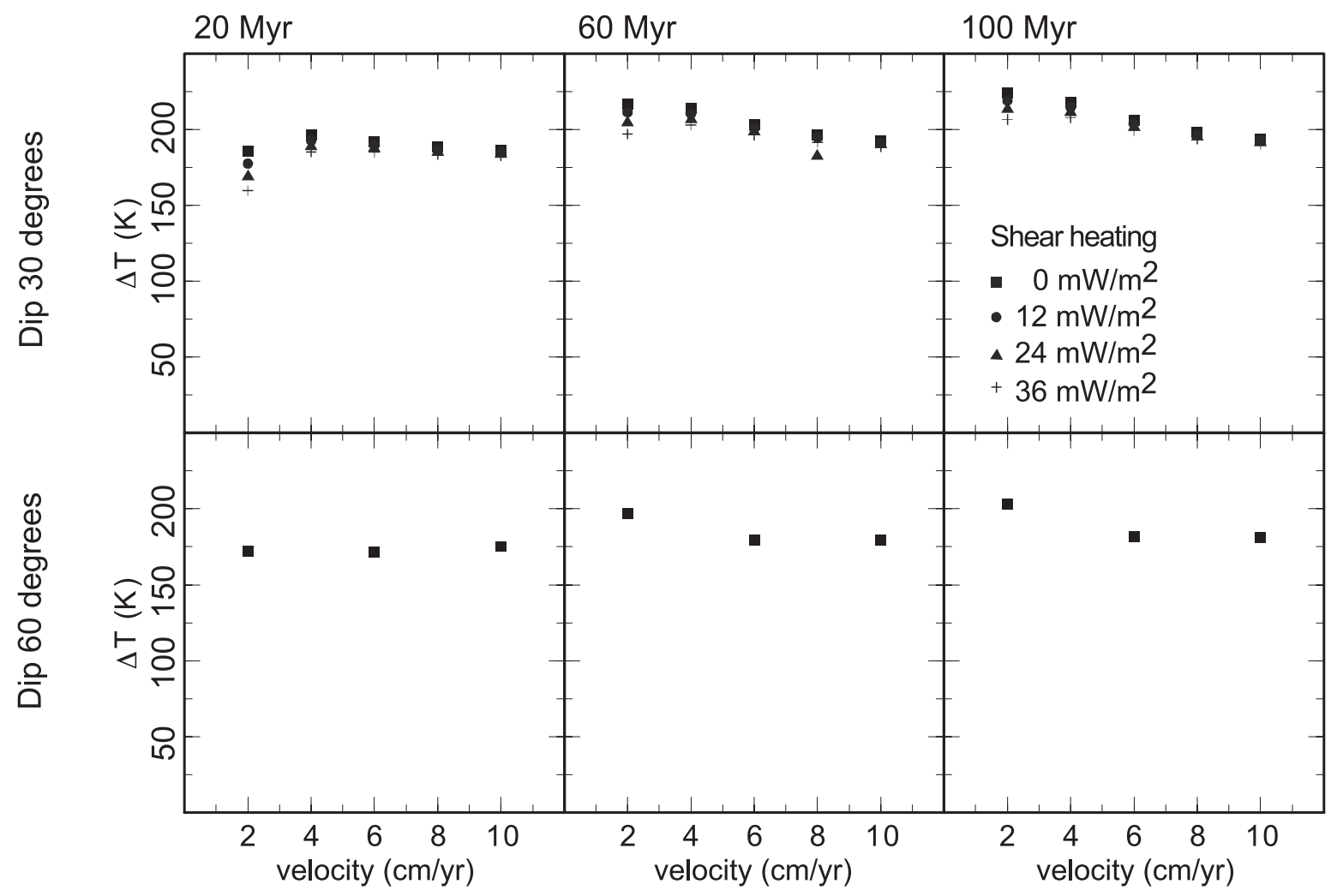

Figure B1. Temperature increase at the top of the slab at $3 \mathrm{GPa}$ caused by a change of isoviscous to olivine rheology in the wedge. Each of the panels shows the change as a function of velocity (from 2 to $10 \mathrm{~cm} / \mathrm{yr}$; horizontal axis) and shear heating rate (from 0 to $36 \mathrm{~mW} / \mathrm{m}^{2}$ ). The top row is for a slab dip of $30^{\circ}$ (as in Figures 2 and 3) and the bottom row corresponds to a slab dip of $60^{\circ}$ (as in Figure 6). From left to right, the age of the incoming lithosphere increases from 20 to $100 \mathrm{Myr}$.

duced with minor variability in all cases. Note that the temperature shift is slightly less in case of high shear heating. This is likely caused by the locally higher temperature and lower viscosity compared to zero shear heating. This causes a reduced coupling between slab and wedge, reduced focusing of the wedge flow, and a subsequently lower temperature increase.

[44] In Figure B2 we have provided predictions of how the dehydration in the crust and mantle will change under variations in subduction zone parameters. Figure B2a shows the PT curves at the top and bottom of the oceanic crust together with the solidus for hydrated basalt (as in Figure 6). The two rows show the differences for the change in slab dip from $30^{\circ}$ to $60^{\circ}$. From left to right, the velocity increases from 2 to $10 \mathrm{~cm} / \mathrm{yr}$. In each graph, we show the PT curves for three different ages of the incoming lithosphere $(20,60$, and 100 Myr). The highest temperature curves represent the youngest lithosphere. Because we use a plate model description (GDH1) of the lithospheric temperature, the differences between 60 and 100 Myr old lithosphere are minor; graphs for older lithosphere would plot very close to those of 100 Myr old lithosphere. Figure B2b provides predictions for the dehydration and/or melting of the top of the mantle portion under the oceanic crust in the same format as Figure B2a, but now with the dehydration curve (yellow) and solidus (black) for lherzolite (as in 7). The shear heating is zero everywhere. We can make a number of observations from these diagrams: (1) melting of the topmost basaltic crust, and by extrapolation the melting of sediments, is predicted for all cases 

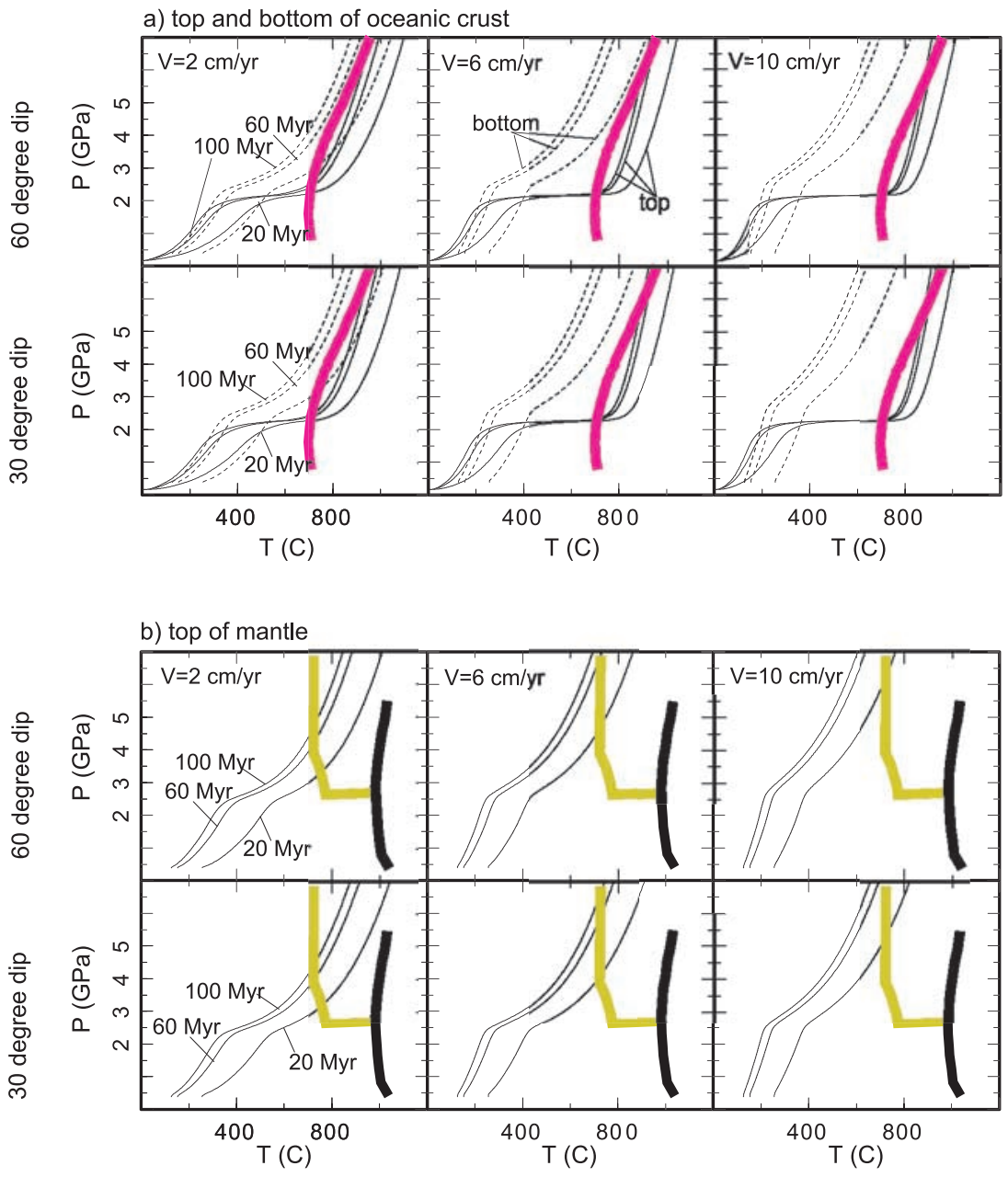

Figure B2. Summary of the PT curves at top and bottom of the subduction oceanic crust as a function of age of the incoming lithosphere (20-100 Myr), subduction speed $(2-10 \mathrm{~cm} / \mathrm{yr})$, and slab dip $\left(30^{\circ}\right.$ and $\left.60^{\circ}\right)$. Shear heating is zero in all cases. The PT curves are plotted on top of the solidus of wet basalt (a) and the dehydration line (yellow) and solidus (black) of hydrated lherzolite (b) as in Figure 7.

which corroborates the findings of Johnson and Plank [1999]. (2) The bottom portion of the oceanic crust remains cool, except for slow slab velocity. Large-scale melting is predicted only for the slowest and youngest subduction zones. (3) We predict dehydration of the top most mantle for all but the fast and old subduction zones. (4) There is no indication of melting of the mantle portion. (5) The increase in subduction zone dip only causes the dehydration reactions and/or melting to occur at slightly higher pressures.

\section{Acknowledgments}

[45] We thank Larry Ruff, Jeff Alt, Scott King, and Patrizia Fumagalli for discussions. SMP thanks the National Science
Foundation for supporting this research through EAR 9809602 .

\section{References}

Abers, G. A., Hydrated subducted crust at 100-250 km depth, Earth Planet. Sci. Lett., 176, 323-330, 2000.

Alt, J. C., and D. A. H. Teagle, Hydrothermal alteration and fluid fluxes in ophiolites and oceanic crust, in Ophiolites and Oceanic Crust: New Insights from Field Studies and Ocean Drilling Program, edited by Y. Dilek et al., pp. 273-282, Geol. Soc. of Am. Spec. Paper, vol. 349, 2000.

Batchelor, G. K., An Introduction to Fluid Dynamics, 615 pp., Cambridge Univ. Press, New York, 1967.

Bebout, G. E., Volatile transfer and recycling at convergent margins: Mass-balance and insights from high-P/T metamorphic rocks (overview), in Subduction, Top to Bottom, Geophys. Monogr., vol. 96, edited by G. E. Bebout et al., pp. 179-194, AGU, Washington, D. C., 1996. 
Bebout, G. E., J. G. Ryan, and W. P. Leeman, B-Be systematics in subduction-related metamorphic rocks: Characterization of the subducted component, Geochim. Cosmochim. Acta, 57, 2227-2237, 1993.

Bostock, M. G., and J. C. VanDecar, Upper mantle structure of the northern Cascadia subduction zone, Can. J. Earth Sci., 32, 1-12, 1995.

Cuvelier, C., A. Segal, and A. A. Van Steenhoven, Finite Element Methods and the Navier-Stokes Equations, D. Reidel, Norwell, Mass., 1986.

Davies, J. H., and D. J. Stevenson, Physical model of source region of subduction zone volcanics, J. Geophys. Res., 97, 2037-2070, 1992.

Dick, H. J. B., et al., A long in situ section of the lower oceanic crust: Results of ODP Leg 176 drilling at the Southwest Indian Ridge, Earth Planet. Sci. Lett., 179, $31-51,2000$.

Fumagalli, P., L. Stixrude, S. Poli, and D. Snyder, The $10 \AA$ phase: A high-pressure expendable sheet silicate stable during subduction of hydrated lithosphere, Earth Planet. Sci. Lett., 186, 125-141, 2001.

Furukawa, Y., Depth of the decoupling plate interface and thermal structure under arcs, J. Geophys. Res., 98, 20,00520,013, 1993.

Furukawa, Y., and S. Uyeda, Thermal state under the Tohoku Arc with consideration of crust heat generation, Tectonophysics, 164, 175-187, 1989.

Helffrich, G. R., Subducted lithospheric slab velocity structure: Observations and mineralogical inferences, in Subduction, Top to Bottom, Geophys. Monogr., vol. 96, edited by G. E. Bebout et al., pp. 215-222, AGU, Washington, D. C., 1996.

Hyndman, R. D., and K. Wang, The rupture zone of Cascadia great earthquakes from current deformation and the thermal regime, J. Geophys. Res., 100, 22,133-22,154, 1995.

Ishikawa, T., and E. Nakamura, Origin of the slab component in arc lavas from across-arc variation of $\mathrm{B}$ and $\mathrm{Pb}$ isotopes, Nature, 370, 205-208, 1994.

Ito, E., D. M. Harris, and A. T. J. Anderson, Alteration of oceanic crust and geologic cycling of chlorine and water, Geochim. Cosmochim. Acta, 47, 1613-1624, 1983.

Johnson M. C., and T. Plank, Dehydration and melting experiments constrain the fate of subducted sediments, Geochem. Geophys. Geosyst., 1, Paper number 1999GC000014, 1999.

Karato, S., Mapping water content in the upper mantle: Mineral physics bases, in Geophysical Monograph Series, edited by J. J. Eiler, AGU, Washington, D. C., in press, 2002.

Karato, S., and P. Wu, Rheology of the upper mantle: A synthesis, Science, 260, 771-778, 1993.

Kincaid, C., and I. S. Sacks, Thermal and dynamical evolution of the upper mantle in subduction zones, J. Geophys. Res., 102, 12,295-12,315, 1997.

Krawczyk C. M., T. J. Reston, M.-O. Beslier, and G. Boillot, Evidence for detachment tectonics on the Iberia abyssal plain rifted margin, in Proceedings of the Ocean Drilling Program, Scientific Results, vol. 149, edited by R. B. Whimarsh et al., pp. 603-615, Ocean Drilling Program, College Station, Tex., 1996.

Leeman, W. P., Boron and other fluid-mobile elements in volcanic arc lavas: Implications for subduction processes, in Subduction, Top to Bottom, Geophys. Monogr., vol. 96, edited by G. E. Bebout et al., pp. 269-276, AGU, Washington, D. C., 1996.

Pawley, A. R., and J. R. Holloway, Water sources for subduction zone volcanism: New experimental constraints, Science, 260, 664-667, 1993.

Peacock, S. M., Fluid processes in subduction zones, Science, 248, 329-337, 1990.

Peacock, S. M., Blueschist facies metamorphism, shear heating, and P-T-t paths in subduction shear zones, J. Geophys. Res., 97, 17,693-17,707, 1992.

Peacock, S. M., Large-scale hydration of the lithosphere above subducting slabs, Chem. Geol., 108, 49-59, 1993.

Peacock, S. M., Thermal and petrological structure of subduction zones (overview), in Subduction, Top to Bottom, Geophys. Monogr., vol. 96, edited by G. E. Bebout et al., pp. 119-134, AGU, Washington, D. C., 1996.

Peacock, S. M., Are the lower planes of double seismic zones caused by serpentine dehydration in subducting oceanic mantle?, Geology, 29, 299-302, 2001.

Peacock S. M., Thermal structure and metamorphic evolution of subducting slabs, in Geophysical Monograph Series, edited by J. Eiler, AGU, Washington, D. C., in press, 2002.

Peacock, S. M., and K. Wang, Seismic consequences of warm versus cool subduction metamorphism: Examples from southwest and northeast Japan, Science, 286, 937939, 1999.

Poli, S., and M. W. Schmidt, $\mathrm{H}_{2} \mathrm{O}$ transport and release in subduction zones: Experimental constraints on basaltic and andesitic systems, J. Geophys. Res., 100, 22,299-22,314, 1995.

Schmidt, M. W., and S. Poli, Experimentally cased water budgets for dehydrating slabs and consequences for arc magma generation, Earth Planet. Sci. Lett., 163, $361-$ 379, 1998.

Seifert K., and D. Brunotte, Geochemistry of the serpentinized mantle peridotite from site 897 in the Iberia abyssal plain, in Proceedings of the Ocean Drilling Program, Scientific Results, vol. 149, edited by R. B. Whimarsh et al., pp. 413-421, Ocean Drilling Program, College Station, Tex., 1996.

Smith, H. J., W. P. Leeman, J. Davidson, and A. J. Spivack, The B isotopic composition of arc lavas from Martinique, Lesser Antilles, Earth Planet. Sci. Lett., 146, 303-314, 1997.

Stein, C. A., and S. Stein, A model for the global variation in oceanic depth and heat-flow with lithospheric age, Nature, 359, 123-129, 1992.

Thompson, A. B., Water in the Earth's mantle, Nature, 358, 295-302, 1992.

Tichelaar, B. W., and L. J. Ruff, Depth of seismic coupling along subduction zones, J. Geophys. Res., 98, 2017-2037, 1993. 
Toksöz, M. N., J. W. Minear, and B. R. Julian, Temperature field and geophysical effects of a downgoing slab, J. Geophys. Res., 76, 1113-1138, 1971.

Ulmer, P., and V. Trommsdorff, Serpentine stability to mantle depths and subduction-related magmatism, Science, 268, 858-861, 1995.

Van der Vorst, H. A., Bi-CGSTAB: A fast and smoothly con- verging variant of Bi-CG for the solution of nonsymmetric linear systems, SIAM J. Sci. Statist. Comput., 12, 631-644, 1992.

Yuen, D. A., L. Fleitout, G. Schubert, and C. Froidevaux, Shear deformation zones along major transform faults and subducting slabs, Geophys. J. R. Astron. Soc., 54, 93-119, 1978 . 